\title{
Structure of many-level adaptive automatic voltage regulation system
}

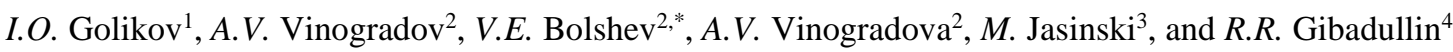 \\ ${ }^{1}$ Orel State Agrarian University, 69 General Rodina St., Orel, 302019, Russia \\ ${ }^{2}$ Federal Scientific Agroengineering Center VIM, 5 1st Institutsky Proezd, Moscow, 109428, Russia \\ ${ }^{3}$ Wroclaw University of Science and Technology, 27 Wybrzeże Wyspiańskiego st., Wrocław, 50-370, Poland \\ ${ }^{4}$ Kazan State Power Engineering University, 51 Krasnoselskaya St., Kazan, 420066, Russia
}

\begin{abstract}
This article describes the features of voltage regulation in electrical networks of 35, 110, 220 $\mathrm{kV}$. The structural diagram of the $35 / 10 / 0.4 \mathrm{kV}$ network is presented. The paper also describes the adaptive automatic voltage regulation system which allows regulating the voltage taking into account the actual voltage values at the consumers' inputs. The structural diagram of the adaptive automatic voltage regulation system in the $0.4 \mathrm{kV}$ electrical network using a boost transformer as an additional means of voltage regulation is given. The system is based on voltage sensors installed in different parts of an eletcrical network sending information on voltage values to to the processing unit which generates a signal for voltage regulating supplied to the executive device and the working body whuch, in turn, change the on-load tapchanger position of a transformer. The paper justifies the need for the enhancement of the adaptive automatic voltage regulation system for different voltage classes wich allows controlling a voltage change at different power supply system levels and regulating voltage level in accordance with this change. For this problem the multi-level adaptive automatic voltage regulation systemis proposed. The system allows regulating the voltage not only in the $0.4 \mathrm{kV}$ network but also in networks of higher voltage classes. The proposed system can be integrated into the structure of intelligent electrical networks.
\end{abstract}

\section{Introduction}

When organizing intelligent electrical networks [1-3], the different elemenents must be considered for e.g.

- load and renewable energy sources production forecasting [4-5],

- power control [6-7],

- smart metering [8-9],

- power quality [10-11],

- security issues [12-13],

- economic dispatch [14-15].

Not indicated but urgent issue is the implementation of adaptive automatic voltage regulation in them. Currently, voltage regulation is automated mainly at substations of $35,110,220 \mathrm{kV}$ using counter regulation by load regulation devices (on-load tap-changers) [1617]. In networks of $0.4 \div 10 \mathrm{kV}$, the regulation by on- load tap-changers is hardly used.

A voltage change in the $35 \div 110 \mathrm{kV}$ network causes a change in voltage in the $6 \div 10 \mathrm{kV}$ distribution network and in the internal $0.4 \mathrm{kV}$ networks of consumers. Obviously, following this change in the electric network parameters, voltage regulation at different voltage levels of the electric network will be required. Figure 1 shows the structural diagram of the $35 / 10 / 0.4 \mathrm{kV}$ network.

\section{Structure of adaptive automatic voltage regulation system}

The use of an adaptive automatic voltage regulation system in rural $10 / 0.4 \mathrm{kV}$ electric networks are considered in works [18-19]. There are the developed methods and technical means for an adaptive automatic

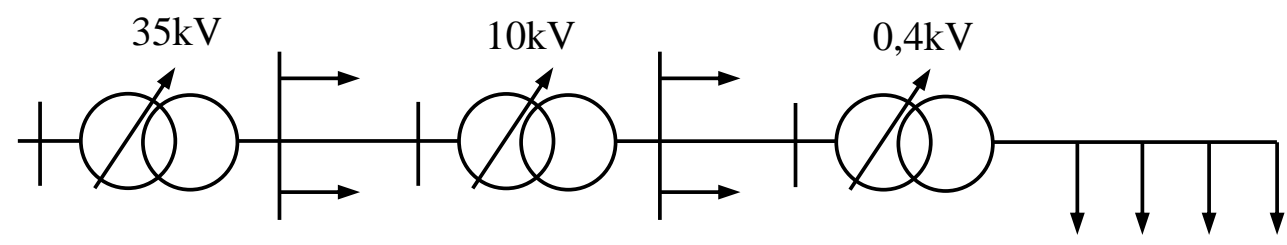

Fig. 1. Structural diagram of the $35 / 10 / 0.4 \mathrm{kV}$ network.

\footnotetext{
* Corresponding author: vadimbolshev@ @mail.com
} 


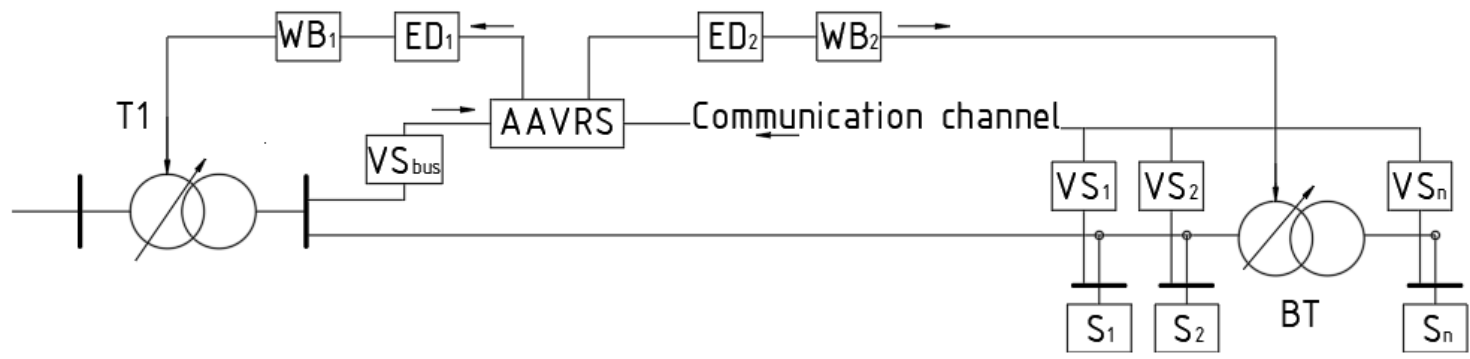

Fig. 2. Structural diagram of AAVRS using a boost transformer as an additional means of voltage regulation.

voltage regulation. According to them, voltage regulation is supposed to be carried out centrally by the on-load tap-changer of a transformer or a stabilizer installed at the beginning of the $0.4 \mathrm{kV}$ power transmission line. Also, regulation options are provided using additional technical means, for example, boost transformers.

Figure 2 presents the structural diagram of the adaptive automatic voltage regulation system (AAVRS) using a boost transformer as an additional means of voltage regulation. Information about the voltage in different parts of the network by sensors VS1, VS2, VSn, VSbus is sent to the AAVRS processing unit. It generates a signal for voltage regulating supplied to the executive device ED1. The executive device ED1 acts on the working body WB1 which changes the on-load tapchanger position of the transformer T1. If it is necessary, the regulation signal is supplied to the executive device ED2 and the working body WB21, which affect the voltage boost transformer BT. Sensors VS1, VS2 are installed at the inputs of consumers S1, S2. The necessary value of voltage regulation is determined to take into account the voltage values measured by all voltage sensors [18]. This system is capable of responding to changes in voltage in a controlled electrical network by adjusting the voltage in a possible range taking into account the characteristics of a transformer on-load tap-changer and a boost transformer.

\section{Structure of many-level Adaptive Automatic Voltage Regulation System}

The enhancement of the adaptive automatic voltage regulation system for different voltage classes will allow controlling a voltage change at different power supply system levels and regulating voltage level in accordance with this change. Figure 3 presents the structural diagram of the many-level AAVRS.

It is proposed to install AAVRS at different voltage levels of an electrical network. So, for example, the AAVRS processing unit installed at the $0.4 \mathrm{kV}$ side controls the voltage deviation at the $0.4 \mathrm{kV}$ electrical network.

For example, if it is impossible to regulate the voltage both by means of the on-load tap-changer of the $10 / 0.4 \mathrm{kV}$ transformer and by means of additional technical means, the AAVRS-4 processing block transmits a signal to the AAVRS-2 processing block about the need for voltage regulation. The AAVRS-2 analyzes the possibility of voltage regulation taking into account the data coming from all other $0.4 \mathrm{kV}$ AAVRS connected to the $10 \mathrm{kV}$ network of $10 / 0.4 \mathrm{kV}$ transformer substation (AAVRS-3, AAVRS-5). The voltage value at the high side of all connected transformers $10 / 0.4 \mathrm{kV}$ is also analyzed. If possible, voltage is regulated at the substation $35 / 10 \mathrm{kV}$ using

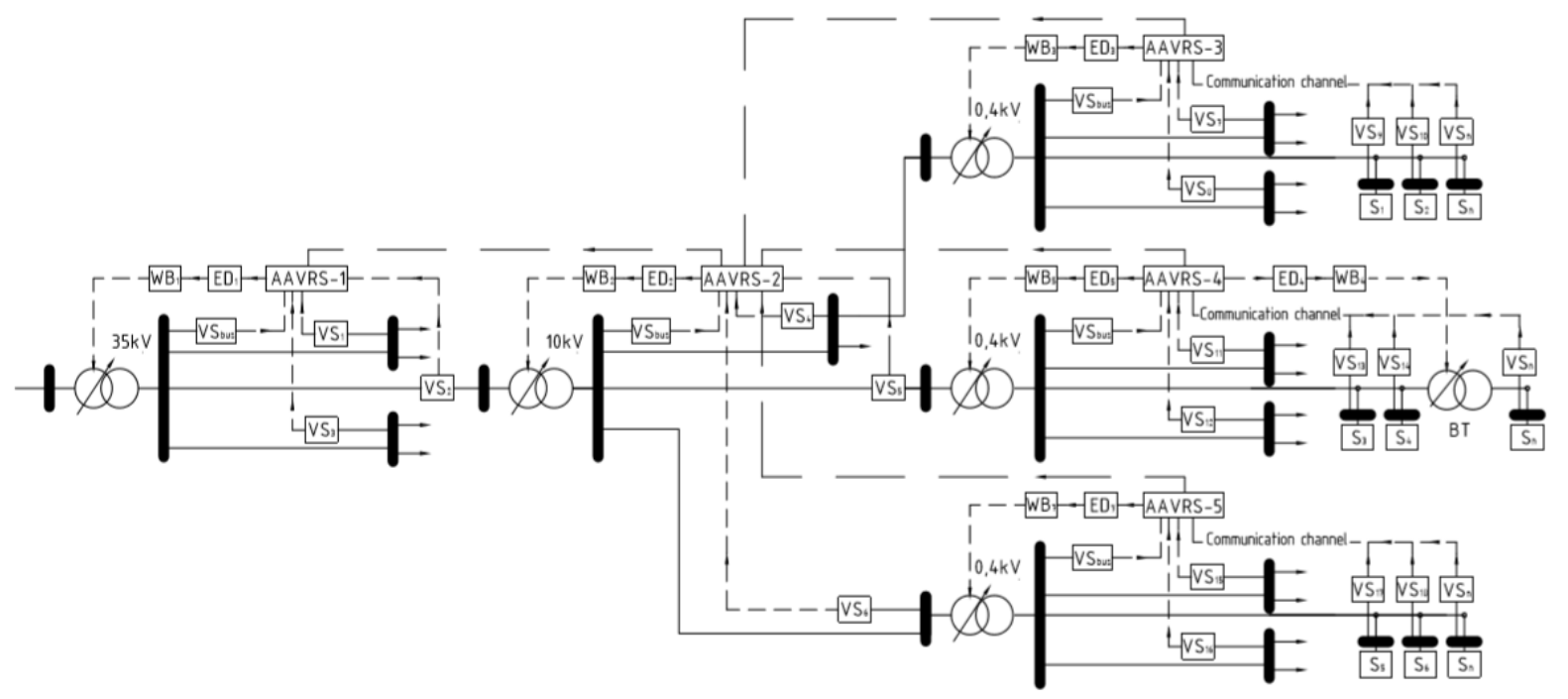

Fig. 3. Structural diagram of the many-level AAVRS. 
AAVRS-2. Similarly, regulation is performed using AAVRS-1 at 110/35 kV transformer substation.

The advantage of this system is its extensibility and it can adapt to electric network operation modes. Such a structure allows regulation taking into account the actual voltage values, that is, the voltage losses that occur in all network elements [20].

The integration of many-level AAVRS into intelligent electric networks can be carried out using the IEC-104, IEC-61850 data protocols and existing data transmission channels and communication tools [21-22]. It can use channels of other systems such as control systems for power quality and power supply reliability [23], smart metering systems [24-25].

\section{Conclusion}

The development of intelligent electric networks also affects the issues of ensuring a stable voltage level at the consumers' inputs. To do this, adaptive automatic voltage regulation systems must be used. The system allows voltage regulation based on the measuring actual voltage values at different electrical network points including at the consumers' inputs. The proposed structure of the many-level adaptive automatic voltage regulation system makes it possible to solve the problem.

\section{References}

[1] A. Arif, Z. Wang, Service restoration in resilient power distribution systems with networked microgrid, Proceedings of the 2016 IEEE Power and Energy Society General Meeting (PESGM), 1-5. DOI: 10.1109/PESGM.2016.7741533 (2016)

[2] J.A. Momoh, Smart grid design for efficient and flexible power networks operation and control, Power Systems Conference and Exposition, PSCE '09, 1-8. DOI: 10.1109/PSCE.2009.4840074 (2009)

[3] A. Ipakchi, F. Albuyeh, Grid of the future, IEEE Power and Energy Magazine 7, 52-62. DOI: 10.1109/MPE.2008.931384 (2009)

[4] Y. Yang, W. Li, T.A. Gulliver, S. Li, Bayesian Deep Learning-Based Probabilistic Load Forecasting in Smart Grids, IEEE Transactions on Industrial Informatics 16, 7, 4703-4713. DOI: 10.1109/TII.2019.2942353

[5] V. Suresh, P. Janik, J. Rezmer, Z. Leonowicz, Forecasting Solar PV Output Using Convolutional Neural Networks with a Sliding Window Algorithm, Energies 13, 3, 723, DOI: 10.3390/en13030723

[6] M. Beccali, L. Bellia, F. Fragliasso, M. Bonomolo, G. Zizzo, G. Spada, Assessing the lighting systems flexibility for reducing and managing the power peaks in smart grids, Applied Energy 268, 114924. DOI: 10.1109/TSG.2019.2942850
[7] M. Jalali, V. Kekatos, N. Gatsis, D. Deka, Designing Reactive Power Control Rules for Smart Inverters Using Support Vector Machines, IEEE Transactions of Smart Grid 11, 2, 17591770. DOI: 10.1109/TSG.2019.2942850

[8] D.L. Donaldson, D. Jayaweera, Effective solar prosumer identification using net smart meter data, International Journal of Electrical Power \& Energy Systems 118, 105823. DOI: 10.1016/j.ijepes.2020.105823

[9] Y. Chawla, A. Kowalska-Pyzalska, P.D. Silveira, Marketing and communications channels for diffusion of electricity smart meters in Portugal, Telematics and Informatics 50, 101385. DOI:10.1016/j.tele.2020.101385

[10] M. Jasiński, et al., Influence of Measurement Aggregation Algorithms on Power Quality Assessment and Correlation Analysis in Electrical Power Network with PV Power Plant, Energies 12, 18, 3547. DOI: $10.3390 /$ en 12183547

[11] W. Grycan, B. Brusilowicz, M. Kupaj, Photovoltaic farm impact on parameters of power quality and the current legislation, Solar Energy 165. DOI: $10.1016 /$ j.solener.2018.03.016

[12] A.W. Altaher, A.H. Hussein, Intelligent security system detects the hidden objects in the smart grid, Indones. J. Electr. Eng. Comput. Sci. 19, 1, 188. DOI: 10.11591/ijeecs.v19.i1

[13] F. Wei, Z. Wan, H. He, Cyber-Attack Recovery Strategy for Smart Grid Based on Deep Reinforcement Learning, IEEE Transactions of Smart Grid 11, 3, 2476-2486. DOI: 10.1109/TSG.2019.2956161

[14] T. Sikorski, et al., A Case Study on Distributed Energy Resources and Energy-Storage Systems in a Virtual Power Plant Concept: Economic Aspects, Energies 12, 23, 4447. DOI: 10.3390/en 12234447

[15] H. Li, Z. Wang, G. Chen, Z.Y. Dong, Distributed Robust Algorithm for Economic Dispatch in Smart Grids Over General Unbalanced Directed Networks, IEEE Transaction of Industrial Informatics 16, 7, 4322-4332. DOI: 10.1109/TII.2019.2945601

[16] C. Vournas, C. Lambrou, M. Glavic, T. Van Cutsem, An integrated autonomous protection system against voltage instability based on Load Tap Changers, In 2010 IREP Symposium Bulk Power System Dynamics and Control - VIII (IREP), 1-14. DOI: 10.1109/IREP.2010.5563286 (2010)

[17] C. Vournas, M. Karystianos, Load tap changers in emergency and preventive voltage stability control, IEEE Transactions on Power Systems 19, 1, 492-498. DOI: 10.1109/TPWRS.2003.818728 (2004)

[18] I.O. Golikov, A.V. Vinogradov, Adaptivnoe avtomaticheskoe regulirovanie napryazheniya $v$ sel'skih elektricheskih setyah 0,38 kV [Adaptive 
automatic voltage regulation in rural electric networks $0.38 \mathrm{kV}$ ] (Publishing House of Orel State Agrarian University, Oryol, Russia, 2016)

[19] A. Vinogradov, A. Vinogradova, I.O. Golikov, V. Bolshev, Adaptive Automatic Voltage Regulation in Rural $0.38 \mathrm{kV}$ Electrical Networks, International Journal of Emerging Electric Power Systems 20, 3. DOI: 10.1515/ijeeps-2018-0269 (2019)

[20] E. Gracheva, A. Alimova, Calculation Methods and Comparative Analysis of Losses of Active and Electric Energy in Low Voltage Devices, In 2019 International Ural Conference on Electrical Power Engineering (UralCon), 361-367. DOI: 10.1109/URALCON.2019.8877627 (2019)

[21] M. Kuzlu, M. Pipattanasomporn, S. Rahman, Communication network requirements for major smart grid applications in HAN, NAN and WAN, Computer Networks 67, 74-88. DOI: 10.1016/j.comnet.2014.03.029 (2014)

[22] E. Ancillotti, R. Bruno, M. Conti, The role of communication systems in smart grids: architectures, technical solutions and research challenges, Communication Technologies 36, 1665-1697. DOI: 10.1016/j.comcom.2013.09.004 (2013)

[23] A. Vinogradov, V. Bolshev, A. Vinogradova, T. Kudinova, M. Borodin, A. Selesneva, N. Sorokin, A System for Monitoring the Number and Duration of Power Outages and Power Quality in $0.38 \mathrm{kV}$ Electrical Networks, In P. Vasant, I. Zelinka, G.W. Weber, (eds) Intelligent Computing \& Optimization, ICO 2018, Advances in Intelligent Systems and Computing 866, 1-10. DOI: 10.1007/978-3-030-00979-3_1 (2019)

[24] Y. Kabalci, A survey on smart metering and smart grid communication, Renewable and Sustainable Energy Reviews 57, 302-318. DOI: 10.1016/j.rser.2015.12.114 (2016)

[25] R.R. Mohassel, A. Fung, F. Mohammadi, K. Raahemifar, A survey on Advanced Metering Infrastructure, Electrical Power and Energy Systems $\quad \mathbf{6 3}, \quad 473-484 . \quad$ DOI: 10.1016/j.ijepes.2014.06.025 (2014) 